\title{
Evaluation Of Subjective Cognitive Function Using The Cognitive Complaints In Bipolar Disorder Rating Assessment (COBRA) In Japanese Adults
}

This article was published in the following Dove Press journal: Neuropsychiatric Disease and Treatment

\author{
Kuniyoshi Toyoshima (D) \\ Takeshi Inoue $\mathbb{D}^{2}$ \\ Jiro Masuya ${ }^{2}$ \\ Masahiko Ichiki ${ }^{2}$ \\ Yota Fujimura ${ }^{2}$ \\ Ichiro Kusumi (D) \\ 'Department of Psychiatry, Graduate \\ School of Medicine, Hokkaido University, \\ Sapporo, Japan; ${ }^{2}$ Department of \\ Psychiatry, Tokyo Medical University, \\ Tokyo, Japan
}

Correspondence: Kuniyoshi Toyoshima Department of Psychiatry, Hokkaido University Graduate School of Medicine, Kita 15, Nishi 7, Sapporo 060-8638, Japan Tel +8|-||-7|6-||6|

Fax +8I-II-706-508I

Email toyoshima@med.hokudai.ac.jp
Purpose: To examine the relationship between depressive symptoms, subjective cognitive function, and quality of life in Japanese adults using the Cognitive Complaints in Bipolar Disorder Rating Assessment (COBRA).

Patients and methods: We evaluated 585 adult community volunteers using the Patient Health Questionnaire-9 (PHQ-9) for evaluation of depressive symptoms and the COBRA for evaluation of subjective cognitive function. We additionally used the 8-item Short-Form Health Survey and the Sheehan Disability Scale to evaluate the quality of life (QoL).

Results: Measures of subjective cognitive function were significantly correlated with depressive symptoms and QoL. Structural equation modeling demonstrated that depressive symptoms directly and indirectly decreased QoL via their effects on subjective cognitive dysfunction. Measures of depressive symptoms were more closely related to QoL than were measures of subjective cognitive function.

Limitations: Study participants were general adult population community volunteers and included healthy people; thus, these results may not be generalizable to patients with depression or bipolar disorder. In addition, the cross-sectional design of this study prevented the identification of causal relationships among the parameters.

Conclusion: Changes in subjective cognitive function may affect QoL via depressive symptoms. Evaluations of subjective cognitive function may help identify factors that reduce QoL.

Keywords: 8-item Short-Form Health Survey, Sheehan Disability Scale, Patient Health Questionnaire-9, QoL, subjective cognitive dysfunction

\section{Introduction}

Quality of life (QoL) of adults from the general population is affected by various factors. A significant association between depressive symptoms and QoL has been shown, and cognitive function has been shown to affect the QoL of workers. ${ }^{1}$ Both depression severity and cognitive symptoms correlate with poor health-related QoL in major depressive disorder. ${ }^{2}$ According to recent research on depression, subjective cognitive function and depression severity correlate with psychosocial function; however, the objective cognitive function does not significantly correlate with psychosocial function. ${ }^{3}$ Lately, the association between subjective cognitive function, depressive symptoms, and QoL has been gaining attention not only in major depressive disorder but also in other mood disorders and with respect to adults in the general population.

Bipolar disorder (BD) is a persistent chronic disorder that is characterized by variations in mood state and energy levels. ${ }^{4} \mathrm{BD}$ affects more than one percent of the 
world's population regardless of nationality, ethnicity, and socioeconomic status. ${ }^{4}$ The fifth edition of the Diagnostic and Statistical Manual of Psychiatric Disorders (DSM-5) ${ }^{5}$ states that the main features of BD are persistent episodes of mania and depression. Although this condition negatively influences the QoL of affected individuals ${ }^{6}$ and is a global source of disability, the biological basis of BD remains generally unknown, and the treatment of this disease is far from satisfactory. ${ }^{7}$ Objective cognitive functions, such as verbal memory and executive functioning as well as subjective cognitive functions, are often impaired in patients with euthymic BD. ${ }^{8,9}$

Neuro-assessment instruments have been used to evaluate the subjective and objective cognitive functions of patients with BD. ${ }^{10-12}$ However, patients with $\mathrm{BD}$, particularly those with hypomanic or manic symptoms, sometimes fail to recognize the significance of their symptoms; ${ }^{13}$ therefore, it is often necessary to assess their subjective cognitive function during remission. The Cognitive Complaints in Bipolar Disorder Rating Assessment (COBRA) is a selfreported instrument that was established by the Bipolar Disorder Program in Barcelona to measure subjective cognitive impairments in patients with $\mathrm{BD} .{ }^{14}$ Indeed, the International Society for Bipolar Disorders Targeting Cognition Task Force recommends that the COBRA be used as an adjunct to objective clinical assessments of cognition. ${ }^{15}$

Although the COBRA has been employed in cognitive impairment studies related to QoL, ${ }^{10}$ these studies are limited. Recently, Toyoshima et $\mathrm{al}^{16}$ proposed a validated Japanese version of the COBRA and applied it to Japanese patients with euthymic $\mathrm{BD}$; this version showed some association between impairment of subjective cognition and QoL. ${ }^{17}$ However, there is limited data regarding the use of the COBRA in the general adult population. The present study, therefore, aimed to assess the relationship between subjective cognition and QoL in the general Japanese adult population using the COBRA. We hypothesized that a decrease or decline in subjective cognitive function would lead to a concomitant decline in QoL.

\section{Materials And Methods}

\section{Research Subjects}

The current study recruited 597 subjects, irrespective of health and psychiatric status, from April 2017 to April 2018 using a convenience sampling method. The study was conducted at the Tokyo Medical University in
Tokyo, Japan, and was approved by the local ethics committee of Tokyo Medical University (approval number, 2016-144). After the nature and purpose of the study were explained to the participants (249 men and 348 women), they provided written informed consent. This study was conducted in accordance with the Declaration of Helsinki.

\section{Assessments}

All subjects were evaluated for subjective cognitive function using the COBRA; QoL, the 8-item Short-Form Health Survey (SF-8); QoL and functional impairment, the Sheehan Disability Scale (SDS); and depressive symptoms, the Patient Health Questionnaire-9 (PHQ-9). Of the 597 subjects who consented to participate, 12 did not complete their questionnaires and were therefore excluded from the analysis. The clinical and sociodemographic data of the remaining 585 subjects were collected (Table 1).

\section{Subjective Cognitive Assessments}

The COBRA utilizes queries informed by everyday mental tasks. Sixteen items, including verbal learning and memory, executive functionality, attention/concentration, working memory, processing speed, and mental tracking, are used to measure subjective cognitive dysfunction, ${ }^{14}$ and a four-point scale is used to rate these items $(0=$ never, $1=$ sometimes, $2=$ often, and $3=$ always). The total COBRA score is calculated by adding the rating of each item; the highest possible score is 48 , and scores of $\geq 15$ indicate moderate to severe subjective cognitive impairment. ${ }^{15}$

This study utilized the Japanese version of the COBRA,${ }^{16}$ which was checked by the original proponents to ensure that the contents retained their originality. Discriminative capacity analysis has shown that a score of 10 obtains the best balance between sensitivity (68.1\%) and specificity $(68.5 \%)$ between bipolar disorder patients and healthy subjects. ${ }^{14}$

\section{Assessment Of QoL}

The 8-item-containing Short-Form Health Survey (SF-8) was also employed to evaluate the health-based dimensions of QoL, ${ }^{18}$ such as vitality, bodily pain, overall health status, cognitive health, and physical functioning. The SF-8 contains a physical component summary (PCS) and a mental component summary (MCS). The PCS includes measures of physical functioning (PF), role-physical (i.e., limits linked to physical problems) (RP), bodily pain (BP), and general health perception (GH). The MCS includes 
Table I Socio-Demographic And Clinical Data

\begin{tabular}{|c|c|c|}
\hline Patient Details & Mean (SD) & n (\%) \\
\hline Age (years) $(n=584)$ & $41.71(12.10)$ & \\
\hline Sex, male, $n(\%)(n=584)$ & & $249(42.6)$ \\
\hline Sex, female, $n(\%)(n=584)$ & & $335(57.4)$ \\
\hline Married, $n(\%)(n=580)$ & & $383(65.5)$ \\
\hline Years of education $(n=585)$ & $14.60(1.82)$ & \\
\hline Currently employed, $n(\%)(n=58 I)$ & & $57 \mid(97.6)$ \\
\hline Psychiatric history, $n(\%)(n=585)$ & & $68(11.6)$ \\
\hline $\begin{array}{l}\text { Current psychiatric treatment, } n(\%) \\
(n=575)\end{array}$ & & $23(3.9)$ \\
\hline $\begin{array}{l}\text { Family history of psychiatric treatment, } \\
n(\%)(n=531)\end{array}$ & & $58(9.9)$ \\
\hline Drinking, $n(\%) \quad(n=584)$ & & $379(63.4)$ \\
\hline Smoking, $n(\%) \quad(n=584)$ & & $114(19.5)$ \\
\hline PHQ-9 $(n=585)$ & $4.05(4.23)$ & \\
\hline SDS work, $(n=580)$ & $2.04(2.52)$ & \\
\hline SDS social $(n=580)$ & $1.72(2.44)$ & \\
\hline SDS family/home $(n=580)$ & $1.52(2.38)$ & \\
\hline SDS total $(n=580)$ & $5.28(6.61)$ & \\
\hline $\operatorname{PF}(n=580)$ & $49.99(5.64)$ & \\
\hline $\operatorname{RP}(n=580)$ & $50.22(5.14)$ & \\
\hline$B P(n=580)$ & $49.87(8.69)$ & \\
\hline $\mathrm{GH}(n=580)$ & $49.27(8.14)$ & \\
\hline VT $(n=580)$ & $49.89(6.7 \mathrm{I})$ & \\
\hline$S F(n=580)$ & $49.12(7.83)$ & \\
\hline $\operatorname{RE}(n=580)$ & $49.59(6.13)$ & \\
\hline$M H(n=580)$ & $49.22(7.56)$ & \\
\hline PCS $(n=580)$ & $49.00(6.30)$ & \\
\hline $\operatorname{MCS}(n=580)$ & $48.44(7.76)$ & \\
\hline COBRA $(n=58 I)$ & $8.32(6.60)$ & \\
\hline
\end{tabular}

Abbreviations: PHQ-9, Patient Health Questionnaire-9; SDS, Sheehan disability scale; PF, physical functioning; RP, role physical; BP, bodily pain; $\mathrm{GH}$, general health; VT, vitality; SF, social functioning; RE, role emotional; $M H$, mental health; PCS, physical component summary; MCS, mental component summary; COBRA, Cognitive Complaints in Bipolar Disorder Rating Assessment.

measures of vitality (VT), social functioning (SF), roleemotional (i.e., limits linked to emotional problems) (RE), and mental health $(\mathrm{MH})$. Each item enquires about health status alterations. The scores of the eight scales and twocomponent summary scores were standardized with the Japanese population norms to obtain mean scores of 50 and standard deviations of 10 (norm-based scoring: NBS). ${ }^{19,20}$ The NBS enables the comparison of the healthrelated QoL among different disease populations.

\section{Measures Of Disability And Impairment}

Sheehan et $\mathrm{al}^{21}$ developed the Sheehan disability scale (SDS), which evaluates global impairment and is made up of three impairment-related items that affect work, social life, family life, and supplementary dimensions of QoL. Researchers such as Endicott et $\mathrm{al}^{22}$ and Arbuckle et $\mathrm{al}^{23}$ have previously applied this tool to patients with BD. The SDS requires patients to rate the degree to which their symptoms affect their work/school, social life, and family life/home obligations on a 10-point visual analog scale. This scale ranges from 0 to $10(0=$ lack of impairment or dysfunction, $1-3=$ mild dysfunction, $4-6=$ moderate dysfunction, 7-9 = marked dysfunction, and $10=$ immense disability). The following question precedes each item: "Have the symptoms disrupted your work/school, social life, and family life/home responsibilities?" The total scores range from 0 to 30; higher scores indicate more disruption in the three domains (i.e., work/school life, social life, and family life) as a result of mental illness. Functional remission was defined as scores $\leq 6 .{ }^{24}$ In primary care settings, over 80 percent of the patients with psychiatric disorders have high SDS scores, while nearly 50 percent of those with high SDS scores have at least one mental disorder. ${ }^{25}$

\section{Measurement Of Depressive Symptoms}

The PHQ-9 is a self-administered questionnaire that may be used to screen for major depressive episodes and measure the extent of depression-associated symptoms. ${ }^{26}$ The Japanese version of the PHQ-9, developed and validated by Muramatsu et $a{ }^{27},{ }^{27}$ was adopted for the present study. This study used a summary score for evaluating the severity of depressive symptoms. Specifically, we calculated the number of times (0-27 points) that patients experienced nine depressive symptoms in the previous 2 weeks using a 4-point Likert scale for each item $(0=$ not at all, $1=$ several days, $2=$ more than half the days, and $3=$ nearly every day). For the Japanese version of PHQ-9, the sensitivity $(90.5 \%)$ and specificity $(76.6 \%)$ were confirmed using the optimal cut-off points $\geq 10$ for depression. ${ }^{28}$ 


\section{Statistical Tests}

Spearman correlations were used to assess the statistical associations between COBRA and QoL (SDS and SF-8), PHQ-9, and clinical parameters (age, sex, married, years of education, currently employed, psychiatric history, current psychiatric treatment, family history of psychiatric treatment, drinking and smoking). A stepwise multiple regression analysis was performed using SDS as the dependent variable and COBRA and PHQ-9 as the independent variables. A stepwise multiple regression analysis was also performed using COBRA as the dependent variable and PHQ-9 and clinical parameters (married, psychiatric history, current psychiatric treatment) as the independent variables. A multiple regression analysis by forced entry method was performed using PHQ-9 as the dependent variable and clinical parameters (married, psychiatric history, current psychiatric treatment) as the independent variables. We also used a covariance structure analysis to assess the relationships among COBRA, PHQ-9, and QoL scores. Mann-Whitney $U$-tests were performed to examine the differences of PHQ-9, SDS, and SF-8 scores between high and low COBRA scores ( $>14$ and $\leq 14$, respectively). All statistical evaluations were performed using SPSS Version 23.0 and Stata 15. In all statistical analyses, $p$-values of $<0.05$ were considered significant. Data are presented as mean \pm SD.

\section{Results}

Clinical and socio-demographic data are shown in Table 1. A total of 585 subjects were included in this study. The mean age and education of participants were $41.19 \pm 12.10$ years and $14.6 \pm 1.82$ years, respectively. Additionally, 249 (42.6\%) participants were men, 571 (97.6\%) were employed, $68(11.6 \%)$ had a psychiatric history, 23 $(3.9 \%)$ were undergoing psychiatric treatment, and 58 $(9.9 \%)$ had a family history of psychiatric treatment. Further, 379 (63.4\%) participants were drinkers, and 114 (19.5\%) were smokers. The scores on the PHQ-9, SDS, PCS, MCS, and COBRA were, $4.05 \pm 4.23,5.28 \pm 6.61$, $49.00 \pm 6.30,48.44 \pm 7.76$, and $8.32 \pm 6.60$, respectively; this was almost the same as the data obtained from healthy Japanese people.

\section{Relationship Between Subjective Cognitive Impairment And QoL}

Following analysis, our results showed a significant correlation between COBRA and QoL scores (Table 2). There
Table 2 Spearman Correlations $(\rho)$ Between COBRA Scores And PHQ-9, Or QoL Measures

\begin{tabular}{|l|l|}
\hline & COBRA \\
\hline PHQ-9 $(n=58 I)$ & $0.407^{* *}$ \\
SDS work $(n=579)$ & $0.363^{* *}$ \\
SDS social $(n=579)$ & $0.378^{* *}$ \\
SDS family/home $(n=579)$ & $0.334^{* *}$ \\
SDS total $(n=579)$ & $0.390^{* *}$ \\
PF $(n=579)$ & $-0.266^{* *}$ \\
RP $(n=579)$ & $-0.294^{* *}$ \\
BP $(n=579)$ & $-0.208^{* *}$ \\
GH $(n=579)$ & $-0.315^{* *}$ \\
VT $(n=579)$ & $-0.290^{* *}$ \\
SF $(n=579)$ & $-0.324^{* *}$ \\
RE $(n=579)$ & $-0.38 I^{* *}$ \\
MH $(n=579)$ & $-0.333^{* *}$ \\
PCS $(n=579)$ & $-0.210^{* *}$ \\
MCS $(n=579)$ & $-0.34 I^{* *}$ \\
\hline
\end{tabular}

Note: $* * p<0.01$ (two-sided).

Abbreviations: COBRA, Cognitive Complaints in Bipolar Disorder Rating Assessment; PHQ-9, Patient Health Questionnaire-9; SDS, Sheehan disability scale; SF-8, Medical Outcomes Study-Short Form Health Survey; PF, physical functions; RP, role physical; BP, bodily pain; GH, general health; VT, vitality; SF, social functioning; RE, role emotional; $\mathrm{MH}$, mental health; $\mathrm{PCS}$, physical component summary; MCS, mental component summary.

were also significant correlations between COBRA scores and SDS or SF-8 scores $(p<0.01)$. These results indicated that impaired subjective cognitive function was associated with a lower QoL.

\section{Relationship Between Subjective Cognitive Impairment And Depressive Symptoms}

As shown in Table 2, there was a significant correlation between COBRA and PHQ-9 scores ( $\rho=0.407, p<0.01)$. This indicated that there was an association between subjective cognitive impairment and depressive symptoms among the general adult population volunteers.

\section{Association Between Subjective Cognitive Impairment, QoL, And Depressive Symptoms}

A stepwise multiple regression analysis was performed to examine the relationships among subjective cognitive impairment, QoL, and depressive symptoms. Results demonstrated that PHQ-9 scores $(\beta=0.519, p<0.001)$ and COBRA scores $(\beta=0.136, p<0.001)$ significantly predicted SDS scores (Adjusted $R^{2}=0.345, p<0.001$; Table 3).

To assess the relationships among COBRA, PHQ-9, and SDS scores, we modeled a structural equation based on the results of the multiple regression analyses. This equation as 
Table 3 Stepwise Multiple Regression Analysis Of The SDS Total Score

\begin{tabular}{|l|l|l|l|l|}
\hline Independent Factors & $\begin{array}{l}\text { Partial Regression } \\
\text { Coefficient (B) }\end{array}$ & 95\% Confidence Interval & $\begin{array}{l}\text { Standardized Partial } \\
\text { Regression Coefficient }(\boldsymbol{\beta})\end{array}$ & $\begin{array}{l}\boldsymbol{P} \\
\text { (Constant) }\end{array}$ \\
PHQ-9 & 0.861 & 0.122 to 1.600 & - & - \\
COBRA & 0.808 & 0.696 to 0.921 & 0.519 & $<0.001$ \\
\hline
\end{tabular}

Notes: Adjusted $R^{2}=0.345, F=151.5, p<0.001$. Dependent factor: SDS total score. Two independent factors: PHQ-9 and COBRA scores.

Abbreviations: COBRA, Cognitive Complaints in Bipolar Disorder Rating Assessment; PHQ-9, Patient Health Questionnaire-9; SDS, Sheehan disability scale.

well as the results of the path coefficients calculated by Stata are shown in Figure 1. The indirect effect of PHQ-9 scores on SDS scores via COBRA scores was $0.06(Z=3.64, p<0.001)$. Fit indices revealed a moderate fit (root mean square error of approximation [RMSEA] $=0.073$, Confirmatory Fit Index $[\mathrm{CFI}]=0.991$, and Tucker-Levis Index $[\mathrm{TLI}]=0.978$ ) According to this model, depressive symptoms not only affected QoL directly, but also affected QoL through subjective cognitive function. To assess the complex relationships among the COBRA, PHQ-9, and SF-8 component summary scores (PCS, MCS), we modeled a structural equation based on the results of the univariate and multiple regression analyses. This equation as well as the results of the path coefficients calculated by Stata are shown in Figure 2. The indirect effect of PHQ-9 on MCS via COBRA was significant: $-0.04(\mathrm{Z}=-2.43, p=0.015)$. However, the indirect effect of PHQ-9 on PCS via COBRA was nonsignificant: -0.03 $(\mathrm{Z}=-1.68, p=0.093)$. Fit indices of the model showed a good fit $($ RMSEA $=0.000$, CFI $=1.000$, TLI $=1.000)$. According to these results, depressive symptoms impact QoL through subjective cognitive function and affect mental QoL more than physical QoL.

Mann-Whitney $U$-tests were performed to examine the differences in PHQ-9, SDS, and SF-8 scores between high

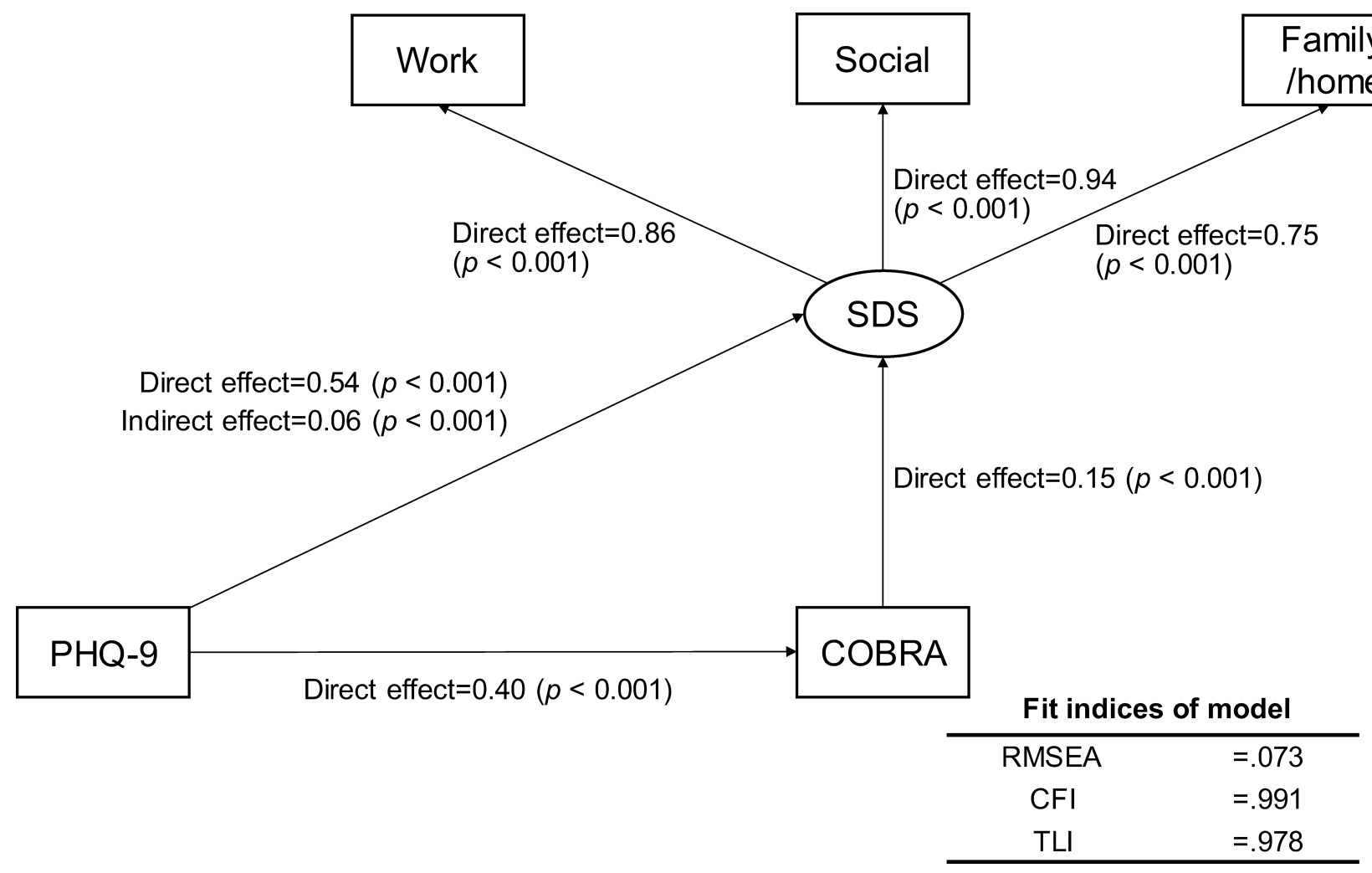

Figure I Results of covariance structure analysis in the structural equation model with depressive symptoms (PHQ-9), subjective cognitive function (COBRA), and quality of life (SDS) in 585 adult volunteer subjects from the community.

Notes: Rectangles indicate the observed variables. The oval indicates the latent variable. The numbers beside the arrows show the standardized path coefficients (minimum $-I$, maximum I).

Abbreviations: PHQ-9, Patient Health Questionnaire-9; COBRA, Cognitive Complaints in Bipolar Disorder Rating Assessment; SDS, Sheehan disability scale. 


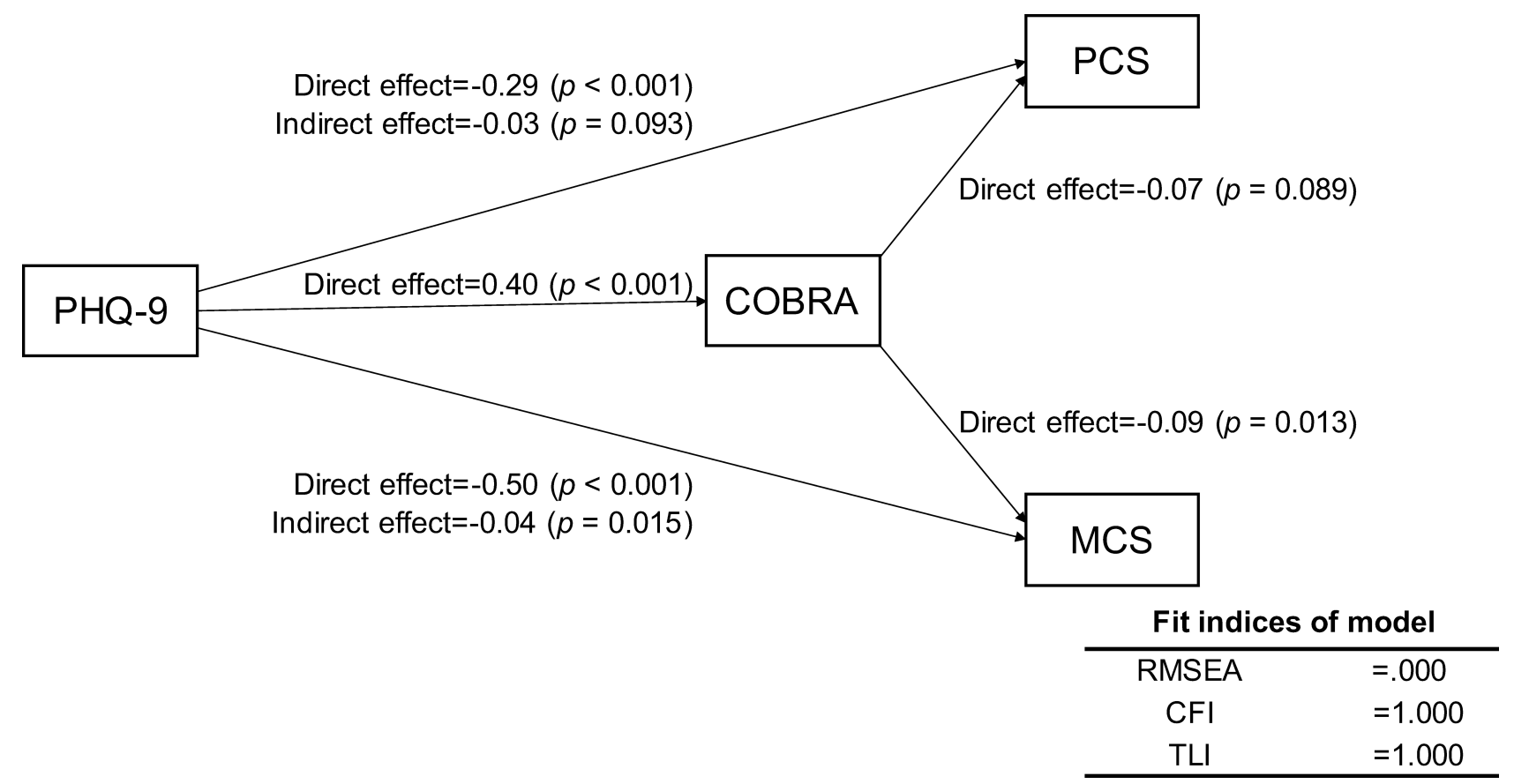

Figure 2 Results of covariance structure analysis in the structural equation model with depressive symptoms (PHQ-9), subjective cognitive function (COBRA), and quality of life (SF-8) in 585 adult volunteer subjects from the community.

Notes: Rectangles indicate the observed variables. The numbers beside the arrows show the standardized path coefficients (minimum $-\mathrm{I}$, maximum $\mathrm{I}$ ).

Abbreviations: PHQ-9, Patient Health Questionnaire-9; COBRA, Cognitive Complaints in Bipolar Disorder Rating Assessment; SF-8, Medical Outcomes Study-Short Form Health Survey; PCS, physical component summary; MCS, mental component summary.

and low COBRA scores. PHQ-9 $(Z=-6.265, p<0.001)$, SDS work $(Z=-5.793, p<0.001)$, SDS social $(Z=-6.35$, $p<0.001)$, SDS family/home $(Z=-5.944, p<0.001)$, SDS total $(Z=-6.32, p<0.001), \operatorname{PCS}(Z=-3.093, p=0.002)$, and MCS $(Z=-5.341, p<0.001)$ scores were significantly different (Table 4).

\section{Relationship Between Subjective Cognition And Clinical Parameters}

Our results demonstrated that there were no significant correlations between subjective cognition and age $(\rho=0.065$, $p=0.120)$ or years of education $(\rho=-0.077 p=0.064)$. The lower COBRA scores were related to "married" $(p=0.03)$, "without a history of psychiatric illness" $(p=0.014)$ and "not being treated for a psychiatric illness" ( $p=0.024)$ (Table 5). Mann-Whitney $U$-tests were performed to investigate the differences in PHQ-9 with respect to married, history of psychiatric illness, and being treated for a psychiatric illness. Married $(\mathrm{Z}=-5.017, p<0.001)$, history of psychiatric illness $(\mathrm{Z}=-5.224, p<0.001)$, and being treated for a psychiatric illness $(Z=-4.436, p<0.001)$ were all significantly different. In other words, "married", "without a history of psychiatric illness", and "not being treated for a psychiatric illness" each had low PHQ-9 scores. A stepwise multiple regression analysis was performed to examine the relationships between subjective cognitive function, depressive symptoms, and clinical parameters (married, psychiatric history, current psychiatric treatment). Results demonstrated that PHQ-9 scores $(\beta=0.380, p<0.001)$ and current psychiatric treatment $(\beta=$ $0.380, p=0.045)$ significantly predicted COBRA scores (Adjusted $R^{2}=0.158, p<0.001$ ), while married and psychiatric history did not predict COBRA scores. A multiple regression analysis by the forced entry method was performed to examine the relationships between depressive symptoms and clinical parameters (married, psychiatric history, current psychiatric treatment). Results demonstrated that psychiatric history $(\beta=0.197, p<0.001)$ and married ( $\beta=-0.189, p<0.001)$ significantly predicted PHQ-9 scores (Adjusted $R^{2}=0.094, p<0.001$ ); however, current psychiatric treatment $(\beta=0.082, p=0.066)$ was not significant.

\section{Discussion}

The results of the present study support the hypothesis that the symptoms of depression are more strongly associated with QoL than is cognitive function in the volunteer population. Previous studies have reported that residual depressive symptoms were strongly associated with QoL in patients with remitted major depressive disorder. $^{29}$ 
Table 4 Relationships Between COBRA Scores And PHQ-9, SDS Work, SDS Social, SDS Total, SDS Family/Home, PCS, And MCS Scores

\begin{tabular}{|c|c|c|c|c|c|c|c|}
\hline & & & $\mathbf{N}$ & \multicolumn{2}{|l|}{ Average Rank } & \multicolumn{2}{|c|}{ Rank Sum } \\
\hline PHQ-9 & \multicolumn{2}{|c|}{$\begin{array}{l}\text { COBRA } \leqq 14 \\
\text { COBRA }>14 \\
\text { Total }\end{array}$} & $\begin{array}{l}480 \\
101 \\
581\end{array}$ & \multicolumn{2}{|l|}{$\begin{array}{l}271.14 \\
385.4\end{array}$} & \multicolumn{2}{|c|}{$\begin{array}{l}130,146 \\
38,925\end{array}$} \\
\hline SDS work & \multicolumn{2}{|c|}{$\begin{array}{l}\text { COBRA } \leqq 14 \\
\text { COBRA }>14 \\
\text { Total }\end{array}$} & $\begin{array}{l}479 \\
100 \\
579\end{array}$ & \multicolumn{2}{|l|}{$\begin{array}{l}272.3 \\
374.79\end{array}$} & \multicolumn{2}{|c|}{$\begin{array}{l}|30,43| .5 \\
37,478.5\end{array}$} \\
\hline SDS social & \multicolumn{2}{|c|}{$\begin{array}{l}\text { COBRA } \leqq 14 \\
\text { COBRA }>14 \\
\text { Total }\end{array}$} & $\begin{array}{l}479 \\
100 \\
579\end{array}$ & \multicolumn{2}{|l|}{$\begin{array}{l}271.11 \\
380.48\end{array}$} & \multicolumn{2}{|c|}{$\begin{array}{l}129,862 \\
38,048\end{array}$} \\
\hline SDS family/home & \multicolumn{2}{|c|}{$\begin{array}{l}\text { COBRA } \leqq 14 \\
\text { COBRA }>14 \\
\text { Total }\end{array}$} & $\begin{array}{l}479 \\
100 \\
579\end{array}$ & \multicolumn{2}{|l|}{$\begin{array}{l}272.67 \\
373.03\end{array}$} & \multicolumn{2}{|c|}{$\begin{array}{l}130,607.5 \\
37,302.5\end{array}$} \\
\hline SDS total & \multicolumn{2}{|c|}{$\begin{array}{l}\text { COBRA } \leqq 14 \\
\text { COBRA }>14 \\
\text { Total }\end{array}$} & $\begin{array}{l}479 \\
100 \\
579\end{array}$ & \multicolumn{2}{|l|}{$\begin{array}{l}270.39 \\
383.93\end{array}$} & \multicolumn{2}{|c|}{$\begin{array}{l}129,517.5 \\
38,392.5\end{array}$} \\
\hline PCS & \multicolumn{2}{|c|}{$\begin{array}{l}\text { COBRA } \leqq 14 \\
\text { COBRA }>14 \\
\text { Total }\end{array}$} & $\begin{array}{l}479 \\
100 \\
579\end{array}$ & \multicolumn{2}{|l|}{$\begin{array}{l}299.82 \\
242.94\end{array}$} & \multicolumn{2}{|c|}{$\begin{array}{l}|43,6| 6 \\
24,294\end{array}$} \\
\hline \multirow[t]{2}{*}{ MCS } & \multicolumn{2}{|c|}{$\begin{array}{l}\text { COBRA } \leqq 14 \\
\text { COBRA }>14 \\
\text { Total }\end{array}$} & $\begin{array}{l}479 \\
100 \\
579\end{array}$ & \multicolumn{2}{|l|}{$\begin{array}{l}306.97 \\
208.74\end{array}$} & \multicolumn{2}{|c|}{$\begin{array}{l}147,036.5 \\
20,873.5\end{array}$} \\
\hline & PHQ-9 & SDS Work & SDS Social & SDS Family/Home & SDS Total & PCS & MCS \\
\hline $\begin{array}{l}\text { Mann-Whitney U } \\
\text { Wilcoxon W } \\
\text { Z } \\
\text { P }\end{array}$ & $\begin{array}{l}14,706 \\
130,146 \\
-6.265 \\
<0.00 \mid\end{array}$ & $\begin{array}{l}|5,47| .5 \\
|30,43| .5 \\
-5.793 \\
<0.00 \mid\end{array}$ & $\begin{array}{l}\mid 4,902 \\
\mid 29,862 \\
-6.35 \\
<0.00 \mid\end{array}$ & $\begin{array}{l}\mid 5,647.5 \\
\mid 30,607.5 \\
-5.944 \\
<0.00 \mid\end{array}$ & $\begin{array}{l}\mid 4,557.5 \\
|29,5| 7.5 \\
-6.32 \\
<0.00 \mid\end{array}$ & $\begin{array}{l}19,24 \\
24,29 \\
-3.09 \\
0.002\end{array}$ & $\begin{array}{l}\mid 5,823.5 \\
20,873.5 \\
-5.34 \mid \\
<0.00 \mid\end{array}$ \\
\hline Grouping variable & \multicolumn{7}{|c|}{ COBRA $\leqq 14$, COBRA $>14$} \\
\hline
\end{tabular}

Note: Analysis was conducted using Mann-Whitney U-tests.

Abbreviations: COBRA, Cognitive Complaints in Bipolar Disorder Rating Assessment; PHQ-9, Patient Health Questionnaire-9; SDS, Sheehan disability scale; SF-8, the 8item-containing Short-Form Health Survey; PCS, physical component summary; MCS, mental component summary.

Another investigation demonstrated that subjective cognitive dysfunction was correlated with measures of QoL in patients with euthymic BD. ${ }^{17}$ Unlike previously published results, the findings of the current study may be representative of the Japanese general adult population. However, further research is needed to determine the relationships between depressive symptoms, cognitive function, and QoL in Japanese adults.

The average COBRA score in this study was $8.32 \pm$ 6.60 , which is lower than previously reported scores of Japanese patients with euthymic BD: e.g., the average COBRA score in a study conducted by Toyoshima et $\mathrm{al}^{16}$ was $13.63 \pm 7.95$. Furthermore, prior studies reported a correlation between subjective cognitive function and $\mathrm{QoL}$ and an association between subjective cognitive function and depressive symptoms in Japanese patients with remitted BD. ${ }^{16,17}$ Similarly, one study demonstrated that both objective and subjective cognitive functions influence QoL in a group of Chinese patients with BD. ${ }^{30}$ However, the relationship between subjective cognitive function and depressive symptoms or QoL has not been examined in the general adult population using the COBRA.

The present study found that depressive symptoms exerted a stronger effect on QoL in the general adult population than did COBRA; this finding may be useful when examining the associations among depression, cognitive function, and QoL using COBRA in patients with remitted $\mathrm{BD}$. The importance of this application is 
Table 5 Chi-Square Test Describing The Association Between COBRA Scores And Demographic Data

\begin{tabular}{|l|l|l|}
\hline & Chi-Square & $\boldsymbol{P}$ \\
\hline Sex & 0.553 & 0.457 \\
Married & 4.712 & 0.03 \\
Current employed & 1.1 & 0.294 \\
Psychiatric history & 5.977 & 0.014 \\
Current psychiatric treatment & 5.089 & 0.024 \\
Family history of psychiatric treatment & 3.016 & 0.082 \\
Drinking & 0.513 & 0.474 \\
Smoking & 1.56 & 0.212 \\
\hline
\end{tabular}

Notes: Chi-square test: COBRA scores $\leqq 14$, COBRA scores $>14$, degree of freedom: I.

highlighted by the hypothesis that cognitive complaints may worsen as QoL declines and BD progresses. ${ }^{31}$ This is also supported by previous reports that patients with $\mathrm{BD}$ who were aware of their cognitive impairment experienced severe chronic symptoms and those who were not cognitively impaired also manifested poor social, occupational, and neuropsychological functioning. ${ }^{32}$

In the future, it will be important to clearly distinguish between BD-induced depression and secondary depression. In this regard, a neuropsychological evaluation may be necessary to delineate cognitive dysfunctions associated with different types of depression. ${ }^{33}$ In this study, current psychiatric treatment significantly predicted subjective cognitive impairment, while psychiatric history did not. This result may indicate that subjective cognitive function is more affected by psychosocial states than temperament characteristics. To investigate these research issues, in the future, we would use a clinimetric approach, which is an innovative clinically based evaluation method for the evaluation of a number of clinical factors that do not fit into the traditional psychometric model. ${ }^{34-36}$

\section{Limitations}

The present study was subject to several limitations. The cross-sectional design of this study prevented the identification of causal relationships among the parameters. However, replicating this study with patients with BD and known healthy controls may help overcome this limitation. Other limitations involve the lack of controls and the heterogeneity among the volunteers regarding their psychiatric health as well as social and educational backgrounds; this diversity may limit the generalizability of the results to patients with affective disorder.

\section{Conclusion}

Although a further systematic investigation is required to reproduce and confirm the generalizability of this study, our data indicated that symptoms of depression rather than subjective cognitive function may be strongly related to QoL in the Japanese general adult population. The present study found that as changes in cognitive function may account for the aggravation of QoL by depressive symptoms, evaluations of cognitive function may help to identify factors affecting the reduction of QoL and inform therapeutic interventions.

\section{Abbreviations}

$\mathrm{BD}$, bipolar disorder; COBRA, Cognitive Complaints in Bipolar Disorder Rating Assessment; SDS, Sheehan disability scale; SF-8, Short-Form Health Survey; PCS, physical component summary; MCS, mental component summary; PF, physical functioning; RP, role-physical; $\mathrm{BP}$, bodily pain; GH, general health perception; VT, vitality; SF, social functioning; RE, role-emotional; $\mathrm{MH}$, mental health; NBS, norm-based scoring; RMSEA, root mean square error of approximation; CFI, Confirmatory Fit Index; TLI, Tucker-Levis Index.

\section{Acknowledgments}

This work was partly supported by a Grant-in-Aid for Scientific Research (no. 16K10194) from the Japanese Ministry of Education, Culture, Sports, Science and Technology, the Research and Development Grants for Comprehensive Research for Persons with Disabilities from the Japan Agency for Medical Research and Development (grant no. JP18dk0307060), and SENSHIN Medical Research Foundation (to $\mathrm{T}$ Inoue). The funding agencies played no role in any of the stages from study design to submission of the paper for publication.

\section{Disclosure}

Dr. Inoue reports personal fees from Mochida Pharmaceutical, Eli Lilly, Janssen Pharmaceutical, MSD, Taisho Toyama Pharmaceutical, Yoshitomiyakuhin, and Daiichi Sankyo, during the conduct of the study; and grants from Shionogi, Astellas, Tsumura, and Eisai; and grants and personal fees from Otsuka Pharmaceutical, Dainippon Sumitomo Pharma, Mitsubishi Tanabe Pharma, Kyowa Pharmaceutical Industry, Pfizer, Novartis Pharma, Takeda Pharmaceutical, and Meiji Seika Pharma; and is a member of the advisory boards of Pfizer, Novartis Pharma, Takeda Pharmaceutical, and 
Mitsubishi Tanabe Pharma. Professor Yota Fujimura reports personal fees from Otsuka Pharmaceutical and honoraria and grants from Novartis Pharma, Otsuka Pharmaceutical, and Shionogi, outside the submitted work. Professor Ichiro Kusumi reports grants from Takeda Pharmaceutical, Boehringer Ingelheim; grants and personal fees from Astellas, Shionogi, Tanabe Mitsubishi Pharma, Otsuka Pharmaceutical, Meiji Seika Pharma, Daiichi Sankyo, Dainippon Sumitomo Pharma, Kyowa Hakko Kirin, Eisai, and Eli Lilly; and personal fees from GlaxoSmithKline, Janssen Pharmaceutical, MSD, Novartis Pharma, Ono Pharmaceutical, Pfizer, Taisho Toyama Pharmaceutical, and Chugai Pharmaceutical. The authors report no other conflicts of interest in this work.

\section{References}

1. Lopes SL, Ferreira AI, Passos AM, Neves M, Sousa C, Sa MJ. Depressive symptomatology, presenteeism productivity, and quality of life: a moderated mediation model. J Occup Environ Med. 2018;60:301-308. doi:10.1097/JOM.0000000000001253

2. Saragoussi D, Christensen MC, Hammer-Helmich L, Rive B, Touya M, Haro JM. Long-term follow-up on health-related quality of life in major depressive disorder: a 2-year European cohort study. Neuropsychiatr Dis Treat. 2018;14:1339-1350. doi:10.2147/NDT. S159276

3. Sumiyoshi T, Watanabe K, Noto $\mathrm{S}$, et al. Relationship of cognitive impairment with depressive symptoms and psychosocial function in patients with major depressive disorder: cross-sectional analysis of baseline data from PERFORM-J. J Affect Disord. 2019;258:172-178. doi:10.1016/j.jad.2019.07.064

4. Grande I, Berk M, Birmaher B, Vieta E. Bipolar disorder. Lancet. 2016;387(10027):1561-1572. doi:10.1016/S0140-6736(15)00241-X

5. American Psychiatric Association. Diagnostic and Statistical Manual of Psychiatric Disorders. 5th ed. Washington, DC: American Psychiatric Association; 2013.

6. Morton E, Murray G, Michalak EE, et al. Quality of life in bipolar disorder: towards a dynamic understanding. Psychol Med. 2018;48 (7):1111-1118. doi:10.1017/S0033291717002495

7. Harrison PJ, Geddes JR, Tunbridge EM. The emerging neurobiology of bipolar disorder. Trends Neurosci. 2018;41(1):18-30. doi:10.1016/ j.tins.2017.10.006

8. Martínez-Arán A, Vieta E, Colom F, et al. Cognitive impairment in euthymic bipolar patients: implications for clinical and functional outcome. Bipolar Disord. 2004;6(3):224-232. doi:10.1111/j.1399. 5618.2004.00111.x

9. Lima FM, Cardoso TA, Serafim SD, et al. Validity and reliability of the Cognitive Complaints in Bipolar Disorder Rating Assessment (COBRA) in Brazilian bipolar patients. Trends Psychiatry Psychother. 2018;40(2):170-178. doi:10.1590/2237-6089-2017-0121

10. Jensen JH, Støttrup MM, Nayberg E, et al. Optimising screening for cognitive dysfunction in bipolar disorder: validation and evaluation of objective and subjective tools. J Affect Disord. 2015;187:10-19. doi:10.1016/j.jad.2015.07.039

11. Demant KM, Vinberg M, Kessing LV, Miskowiak KW. Assessment of subjective and objective cognitive function in bipolar disorder: correlations, predictors and the relation to psychosocial function. Psychiatry Res. 2015;229(1-2):565-571. doi:10.1016/j.psychres.2015.05.022
12. Sumiyoshi T, Toyomaki A, Kawano N, et al. Verbal memory impairment in patients with subsyndromal bipolar disorder. Front Psychiatry. 2017;8:168. doi:10.3389/fpsyt.2017.00297

13. Vieta E, Berk M, Schulze TG, et al. Bipolar disorders. Nat Rev Dis Primers. 2018;4:18008. doi:10.1038/nrdp.2018.8

14. Rosa AR, Mercadé C, Sánchez-Moreno J, et al. Validity and reliability of a rating scale on subjective cognitive deficits in bipolar disorder (COBRA). J Affect Disord. 2013;150(1):29-36. doi:10.1016/j.jad.2013.02.022

15. Miskowiak KW, Burdick KE, Martinez-Aran A, et al. Assessing and addressing cognitive impairment in bipolar disorder: the International Society for Bipolar Disorders Targeting Cognition Task Force recommendations for clinicians. Bipolar Disord. 2018;20(3):184-194. doi:10.1111/bdi.12595

16. Toyoshima K, Fujii Y, Mitsui N, et al. Validity and reliability of the Cognitive Complaints in Bipolar Disorder Rating Assessment (COBRA) in Japanese patients with bipolar disorder. Psychiatry Res. 2017;254:85-89. doi:10.1016/j.psychres.2017.04.043

17. Toyoshima K, Kako Y, Toyomaki A, et al. Associations between cognitive impairment and quality of life in euthymic bipolar patients. Psychiatry Res. 2019;271:510-515. doi:10.1016/j.psychres.2018.11.061

18. Ware JE, Kosinski M, Dewey JE, Gandek B. How to Score and Interpret Single-Item Health Status Measures: A Manual for Users of the SF-8 Health Survey. Lincoln, RI: QualityMetric, Inc.; Boston, MA: Health Assessment Lab; 2001.

19. Fukuhara S, Bito S, Green J, Hsiao A, Kurokawa K. Translation, adaptation, and validation of the SF-36 Health Survey for use in Japan. J Clin Epidemiol. 1998;51(11):1037-1044. doi:10.1016/ s0895-4356(98)00095-x

20. Fukuhara S, Ware JE Jr, Kosinski M, Wada S, Gandek B. Psychometric and clinical tests of validity of the Japanese SF-36 Health Survey. J Clin Epidemiol. 1998;51(11):1045-1053. doi:10.1016/s0895-4356(98)00096-1

21. Sheehan DV, Harnett-Sheehan K, Raj BA. The measurement of disability. Int Clin Psychopharmacol. 1996;11(Suppl 3):89-95. doi:10.1097/00004850-199606003-00015

22. Endicott J, Paulsson B, Gustafsson U, Schiöler H, Hassan M. Quetiapine monotherapy in the treatment of depressive episodes of bipolar I and II disorder: improvements in QoL and quality of sleep. J Affect Disord. 2008;111(2-3):306-319. doi:10.1016/j.jad.2008.06.019

23. Arbuckle R, Frye MA, Brecher M, et al. The psychometric validation of the Sheehan Disability Scale (SDS) in patients with bipolar disorder. Psychiatry Res. 2009;165(1-2):163-174. doi:10.1016/j. psychres.2007.11.018

24. Sheehan DV, Harnett-Sheehan K, Spann ME, Thompson HF, Prakash A. Assessing remission in major depressive disorder and generalized anxiety disorder clinical trials with the discan metric of the Sheehan disability scale. Int Clin Psychopharmacol. 2011;26(2):75-83. doi:10.1097/YIC.0b013e328341bb5f

25. Leon AC, Olfson M, Portera L, Farber L, Sheehan DV. Assessing psychiatric impairment in primary care with the Sheehan Disability Scale. Int J Psychiatry Med. 1997;27(2):93-105. doi:10.2190/T8EMC8YH-373N-1UWD

26. Spitzer RL, Kroenke K, Williams JB. Validation and utility of a selfreport version of PRIME-MD: the PHQ primary care study. Primary Care Evaluation Of Mental Disorders. Patient Health Questionnaire. JAMA. 1999;282(18):1737-1744. doi:10.1001/jama.282.18.1737

27. Muramatsu K, Miyaoka H, Kamijima K, et al. The patient health questionnaire, Japanese version: validity according to the mini-international neuropsychiatric interview-plus. Psychol Rep. 2007;101(3 Pt 1):952-960. doi:10.2466/pr0.101.3.952-960

28. Muramatsu K, Miyaoka H, Kamijima K, et al. Performance of the Japanese version of the Patient Health Questionnaire-9 (J-PHQ-9) for depression in primary care. Gen Hosp Psychiatry. 2018;52:64-69. doi:10.1016/j.genhosppsych.2018.03.007 
29. Shimizu Y, Kitagawa N, Mitsui N, et al. Neurocognitive impairments and quality of life in unemployed patients with remitted major depressive disorder. Psychiatry Res. 2013;210(3):913-918. doi:10.1016/j. psychres.2013.08.030

30. Xiao L, Gao Y, Zhang L, Chen P, Sun X. The relationship between cognitive function and quality of life in euthymic Chinese patients with bipolar disorder. Psychiatry Res. 2016;246:427-431. doi:10.1016/j. psychres.2016.10.026

31. Tatay-Manteiga A, Cauli O, Tabarés-Seisdedos R, Michalak EE, Kapczinski F, Balanzá-Martínez V. Subjective neurocognition and quality of life in patients with bipolar disorder and siblings. $J$ Affect Disord. 2019;245:283-288. doi:10.1016/j.jad.2018.11.012

32. Martínez-Arán A, Vieta E, Colom F, et al. Do cognitive complaints in euthymic bipolar patients reflect objective cognitive impairment? Psychother Psychosom. 2005;74(5):295-302. doi:10.1159/000086320
33. Lin X, Lu D, Huang Z, Chen W, Luo X, Zhu Y. The associations between subjective and objective cognitive functioning across manic or hypomanic, depressed, and euthymic states in Chinese bipolar patients. J Affect Disord. 2019;249:73-81. doi:10.1016/j.jad.2019.02.025

34. Fava GA, Carrozzino D, Lindberg L, Tomba E. The clinimetric approach to psychological assessment: a tribute to per bech, MD (1942-2018). Psychother Psychosom. 2018;87(6):321-326. doi:10.1159/000493746

35. Carrozzino D. Clinimetric approach to rating scales for the assessment of apathy in Parkinson's disease: a systematic review. Prog Neuropsychopharmacol Biol Psychiatry. 2019;2019(94):109641. doi:10.1016/j.pnpbp.2019.109641

36. Carrozzino D, Svicher A, Patierno C, Berrocal C, Cosci F. The euthymia scale: a clinimetric analysis. Psychother Psychosom. 2019;88(2):119-121. doi:10.1159/000496230

\section{Publish your work in this journal}

Neuropsychiatric Disease and Treatment is an international, peerreviewed journal of clinical therapeutics and pharmacology focusing on concise rapid reporting of clinical or pre-clinical studies on a range of neuropsychiatric and neurological disorders. This journal is indexed on PubMed Central, the 'PsycINFO' database and CAS, and is the official journal of The International Neuropsychiatric Association (INA). The manuscript management system is completely online and includes a very quick and fair peer-review system, which is all easy to use. Visit http://www.dovepress.com/testimonials.php to read real quotes from published authors. 